\title{
Verständigungsprobleme durch anthropogene Einträge?
}

\author{
Der Infochemikalien-Effekt
}

\author{
Ursula Klaschka
}

Erhalten: 25. Februar 2009/Akzeptiert: 29. Mai 2009/Online veröffentlicht: 7. Juli 2009

(C) Springer-Verlag 2009

Zusammenfassung Hintergrund Organismen können chemische Signale in ihrer Umgebung, sogenannte Infochemikalien, deuten und als Informationsquelle nutzen, um adäquat auf ihre biotische und abiotische Umgebung zu reagieren. Diese chemische Kommunikation spielt eine entscheidende Rolle bei lebenswichtigen Aktivitäten wie Fortpflanzung, Sozialverhalten, Nahrungsaufnahme, Verteidigung und Orientierung und ist damit essenziell für das Überleben eines Individuums oder einer Art.

Vorgehensweise Der Transfer der Kenntnisse über natürliche Infochemikalien aus der chemischen Ökologie auf die Ökotoxikologie führt zu der Beschreibung des Infochemikalien-Effekts. In einem zweiten Schritt werden Möglichkeiten zur Quantifizierung des Infochemikalien-Effekts entwickelt. Dazu wird die schrittweise Abfolge von der Geruchsemission bis zu den Reaktionen von Empfängerorganismen als Basis zu Systematisierung verwendet und geeignete Testansätze, die sich in der Grundlagenforschung bewährt haben, vorgestellt.

Ergebnisse In den vergangenen Jahren wurden große Fortschritte bei der Aufklärung der chemischen Kommunikation von Umweltorganismen gemacht. Es wird immer deutlicher, wie komplex diese chemische „Sprache“ ist und wie wenig darüber bisher bekannt ist. Infochemikalien werden von biotischen oder abiotischen Sendern emittiert und von Empfängern wahrgenommen. Die relevanten Konzentrationen sind sehr gering, zum Teil im nano- bis pikomolaren Bereich. Die Organismen können auf sehr spezifische Weise auf Infochemikalien reagieren, durch ihr Verhalten oder durch morphologische oder physiologische Veränderungen. Es gibt stichhaltige Indi-

Ursula Klaschka $(\square)$

Hochschule Ulm,

Prittwitzstr. 10, 89075 Ulm, Deutschland

E-Mail:klaschka@hs-ulm.de zien dafür, dass vom Menschen in die Umwelt eingetragene Stoffe, z. B. Duftstoffe aus Kosmetika oder Wasch- und Reinigungsmitteln, die chemische Kommunikation von Umweltorganismen beeinflussen. Diese Wirkung heißt Infochemikalien-Effekt (engl. Infochemical Effect). Es liegt nahe, dass eine Störung der chemischen Kommunikation sogar bedeutendere Folgen für das Überleben einer Population haben kann als direkte toxische Effekte: Reduzierte Nahrungsaufnahme, das Nichterkennen eines Feindes, gestörtes Sexualverhalten oder anderes unpassendes Verhalten kann zum Rückgang einer Population führen, auch wenn die Individuen völlig gesund sind. Eine Abschätzung der Bedeutung des InfochemikalienEffekts für die reale Umwelt verlangt nach quantifizierbaren Laborresultaten. Um dafür Methoden zu entwickeln, wurden mögliche experimentelle Ansätze systematisch zusammengestellt. Die vorgestellten Tests basieren auf der Kenntnis der genetischen Sequenzen für Riechrezeptoren, von Bindungsstudien für Duftstoffe, der Signalweiterleitung und der Reaktionen der Empfänger auf der Ebene des Einzelorganismus oder der Population. Der Schwerpunkt dieser Studie liegt bei aquatischen tierischen Organismen.

Diskussion Die Ergebnisse machen deutlich, dass das derzeitige Verständnis der Wechselwirkungen von Organismen im Ökosystem noch unvollständig ist und wir weit davon entfernt sind, die Interaktionen zwischen den belebten und den unbelebten Elementen des Ökosystems nachvollziehen zu können. Die vorliegende Zusammenstellung kann nicht vollständig sein, sondern soll als Diskussionsbasis und Ausgangspunkt für weitere Untersuchungen dienen.

Schlussfolgerungen Mit der Beschreibung des Infochemikalien-Effekts wird ein neues Kapitel in der Ökotoxikologie aufgeschlagen. Dieser neue, sehr empfindliche Endpunkt könnte realistischere Aussagen über die Wirkung von Umweltchemikalien auf das Ökosystem erlauben, als es bisher möglich ist. 
Empfehlungen und Ausblick Die Diskrepanz zwischen der biologischen Bedeutung und den geringen Kenntnissen über natürliche und anthropogene Infochemikalien in der Umwelt legt nahe, dass weitere Forschungen dringend notwendig sind. Die Entdeckung des Infochemikalien-Effekts kann mit der Entdeckung der endokrinen Wirkungen von Umweltchemikalien verglichen werden. Zur Erfassung des Infochemikalien-Effekts für die regulatorische Ökotoxikologie werden verbesserte oder neue Methoden zur Erkennung dieses Wirkmechanismus erforderlich sein. Die wichtigste Konsequenz ist, dass die Beschäftigung mit dem Infochemikalien-Effekt zu einem ganz neuen Verständnis der Komplexität von Lebensgemeinschaften in unserer Umwelt führen wird.

Begriffsbestimmungen Infochemikalien sind chemische Stoffe im Wasser oder der Luft, die einen Organismus über seine Umgebung informieren. Infochemikalien können von Sendern aktiv oder passiv emittiert werden und von Empfängern wahrgenommen werden.

Natürliche Infochemikalien sind Infochemikalien, die Organismen in einer vom Menschen unbeeinflussten Umwelt emittieren oder wahrnehmen.

Anthropogene Infochemikalien sind Stoffe, die vom Menschen in die Umwelt eingetragen werden und für den Infochemikalien-Effekt verantwortlich sind.

Der Infochemikalien-Effekt ist eine Reaktion des Organismus auf anthropogene Infochemikalien.

Schlüsselwörter Chemische Kommunikation . Chemische Ökologie · Chemoperzeption · Duftstoffe · Infochemikalien · Infochemical Effect · Infochemikalien-Effekt · Geruchssinn · Subletale Wirkungen

\section{Do anthropogenic discharges lead to difficulties in communication? The Infochemical Effect}

\footnotetext{
Abstract Background Organisms can perceive chemical signals in their environment, so-called infochemicals, and use them as information source to react adequately to their abiotic and biotic environment. This chemical communication plays a prevalent role for vital activities such as reproduction, behavior, food uptake, defense or orientation and is therefore essential for the survival of an individual or a species.

Main features The findings on natural infochemicals in chemical ecology were combined with ecotoxicology and lead to the description of the infochemical effect. Different approaches for quantification of the infochemical effect are developed in a second step. The complete sequence from the emission of odorants up to the reactions of the receiver
}

organisms outlines a systematic procedure and allows to present test systems that proved to be useful in basic research originally and that might be suitable for the determination of the infochemical effect in future.

Results The research on chemical communication of environmental organisms made great progress in the passed years. The results show how complex this "language" is and how little we know up to now. Infochemicals are emitted by biotic or abiotic senders and perceived by receivers. The relevant concentrations are very low, down to the nano- or pikomolar range. The organisms can react in very specific ways to infochemicals, by their behavioral, morphological or physiological adaptations. There are strong indications that anthropogenic discharges, such as fragrances in personal care products or in washing and cleansing products, influence the chemical communication of environmental organisms. This effect is called infochemical effect. It suggests itself that a disruption of the chemical communication might have more serious consequences for the survival of a population than direct toxic effects. Reduced food uptake, the non-recognition of a predator, impaired sexual behavior or other unsuitable reactions can lead to a decrease of the population even if the individuals are perfectly healthy. The relevance of the infochemical effect for the real nature can only be evaluated by quantification with laboratory tests. Experimental approaches were compiled systematically and served as basis to select suitable methods for the measurement of the infochemical effect. The methods presented here depend on the knowledge on the genetic sequences for the olfactory receptors, on binding studies of odorants, on signal transduction and on the reactions of the receivers on the level of single organisms or populations. The main focus is on aquatic animals.

Discussion The results show that the actual unterstanding of the interactions of organisms in the ecosystem is incomplete. We are far from comprehending the interplay between inanimate and live elements of the ecosystem. The compilation presented here cannot be complete but should serve as a point of depart for further discussion and research.

Conclusions The description of the infochemical effect opens a new chapter in ecotoxicology. This new and very sensitive end point could yield a more realistic picture about the effects environmental chemicals have in the ecosystem compared to the picture we have up to now.

Recommendations and perspectives The discrepancy between the biological relevance and the lack of knowledge about natural and anthropogenic infochemicals in the environment demands further research urgently. The discovery of the infochemical effect can be compared with the discovery of endocrine disruptors. Improved new methods will be needed to register and elucidate the mode of action of the infochemical effect for regulatory ecotoxicology. The engagement in the study of the infochemical effect will lead 
to a new understanding of the complexity of biocoenoses in our environment, probably the most important perspective of this work.

Keywords Chemical communication $\cdot$ Chemical ecology · Chemoperception · Fragrances · Infochemicals · Infochemical effect $\cdot$ Olfaction $\cdot$ Sublethal effects

\section{Verständigung mit Gerüchen}

Eine Elritze muss ihren Feind nicht sehen, um zu wissen, dass in der Nähe Hechte sind, um zu wissen, wie groß und

wie zahlreich diese sind, ob sie hungrig sind und $o b$ diese Hechte zurzeit Elritzen fressen. Sie kann all diese Information riechen!

(Chivers und Mirza 2001; Ferrari und Chivers 2006b; Ferrari et al. 2006a,b; Kusch et al. 2004)

\subsection{Komplexe chemische Kommunikationsnetze}

Organismen werden täglich mit einer Vielzahl an Reizen aus der Umgebung konfrontiert, die sie wahrnehmen und interpretieren, um ihre Aktivitäten wie Futtersuche, Flucht, Verteidigung oder Fortpflanzung darauf abzustimmen. Die chemische Zusammensetzung der Umgebung spielt dabei eine herausragende Rolle. Die Stoffe im Wasser oder in der Luft, die einen Organismus über seine Umgebung informieren, heißen Infochemikalien. Es kommen immer mehr Fakten ans Tageslicht, die ahnen lassen, wie komplex die chemischen Kommunikationssysteme sind. Die meisten Organismen leben in einer eigenen „Duftwelt“, für die sie besonders sensibilisiert sind (z.B. Atzmüller und Grammer 2000; Brönmark und Hansson 2000; Burks und Lodge 2002; Chivers und Smith 1998; Dodson et al. 1994; Hilker und McNeil 2007; Johansson und Jones 2007; Klaschka 2008a,b; Stacey 2003; Webster et al. 2007; Wyatt 2003; Zimmer und Butman 2000). Für Organismen, die im Wasser leben, bringt es entscheidende Vorteile, wenn sie sich auf chemische Reize verlassen, da diese auch bei Nacht oder in trübem Wasser zuverlässige Informationen liefern. Die Geruchssignale sind ideal für mittlere Zeitfenster geeignet: Ein Geruchsreiz hält länger an als ein Laut oder ein vorübergehendes visuelles Signal wie eine Bewegung und ist von kürzerer Lebensdauer als eine morphologische Änderung. Geruchssignale können durch Diffusion oder Abbau der Stoffe verschwinden. Sie sind auch gut für mittlere räumliche Größenordnungen geeignet, denn sie reichen nicht so weit wie ein penetranter Ton, aber sie reichen weiter als eine Berührung oder Geschmacksreize. Beim Geruchssinn gibt es im Gegensatz zu Licht und Schall keine lineare Skala der Wellenlängen und Frequenzen, sondern eine unbegrenzte Vielzahl an Geruchsqualitäten, in Abhängigkeit von den Riechstoffen und den Riechrezeptoren der Empfänger. Ein weiterer wichtiger Grund für die Universalität der chemischen Kommunikation ist die Tatsache, dass Chemikalien die biochemische Signaltransduktion direkt induzieren können, ohne dass ein physikalischer Reiz in eine biochemische Reaktion transformiert werden muss wie bei Licht- und Schallwahrnehmung.

Biotische oder abiotische Sender geben absichtlich oder unabsichtlich Infochemikalien ab, Empfänger registrieren diese und reagieren darauf. Man kann sich die chemische Kommunikation wie ein kompliziertes dynamisches Netzwerk vorstellen, in dem ein Sender mehr als eine Infochemikalie in verschiedenen Konzentrationen und $\mathrm{zu}$ verschiedenen Zeiten emittiert und ein Empfänger viele Infochemikalien gleichzeitig von vielen Quellen empfängt (Abb. 1). Umweltorganismen werden mit Infochemikalien von Artgenossen (Partner, Konkurrenten, Familienmitglieder, Nachkommen), Futter/Beute, Räubern, anderen Organismen oder aus anderen Quellen konfrontiert. Auch Menschen sind Sender und Empfänger von Infochemikalien. Die Gerüche des eigenen Körpers, des Partners oder der eigenen Kinder sind uns wohlvertraut. Bei genauer Betrachtung spielt der Geruchssinn auch für den Menschen eine wichtige Rolle, aber die Komplexität und die feine Abstimmung der chemischen Kommunikation von Umweltorganismen ist für uns schwer vorstellbar, wie die Beispiele in diesem Artikel zeigen.

\subsection{Natürliche Infochemikalien}

Infochemikalien werden durch Chemoperzeption von entfernten Signalen wahrgenommen, bei den meisten Organismen durch den Geruchssinn. Daher sind natürliche Infochemikalien meist Geruchsstoffe, d.h. bei terrestrischen Organismen relativ kleine, unpolare Moleküle mit einem gewissen Dampfdruck, bei aquatischen Organismen auch größere Moleküle mit einer größeren Polarität. Ein Stoff kann für eine Art oder für mehrere eine Infochemikalie sein. Sie können intraspezifisch fungieren, wenn Sender und Empfänger zu selben Art gehören (z.B. Pheromone) oder interspezifisch, wenn Sender und Empfänger zu verschiedenen Arten gehören (z. B. Blütendüfte). Erst seit den vergangenen Jahren liegen Resultate über die chemische Identität von Infochemikalien vor. Viele Ergebnisse gibt es für terrestrische Insekten (z. B. Pelosi et al. 2006); für aquatische Organismen sind die detaillierten Erkenntnisse eher spärlich. Die beschriebenen Infochemikalien gehören $\mathrm{zu}$ verschiedenen chemischen Gruppen und wurden z.B. als Proteine, Peptide, Aminosäuren, Kohlenhydrate, Kohlenwasserstoffe, Aldehyde, Karbonsäuren, Lipide, Lactone, Steroide, Phenole, Terpene, Phosphatidylcholine oder 
Abb. 1 Schematische vereinfachte Darstellung der Komplexität der Kommunikationsnetzwerke durch Infochemikalien. Sender können verschiedene Substanzen emittieren, die für verschiedene Empfänger Infochemikalien sein können. Empfänger können auf bestimmte Infochemikalien mit unterschiedlichen Reaktionen antworten. Die Pfeile in der Abbildung stellen die Verhältnisse exemplarisch dar. In der Natur gibt es natürlich mehr als jeweils drei Sender, Infochemikalien und Empfänger. Interne Faktoren, wie Alter, Größe, Sättigung etc. und externe Faktoren wie Lichtverhältnisse, Temperatur, Nahrungsvorrat und die Anwesenheit von anderen Organismen können die verschiedenen Stufen beeinflussen (s. Abb. 4, nach Klaschka 2008b)

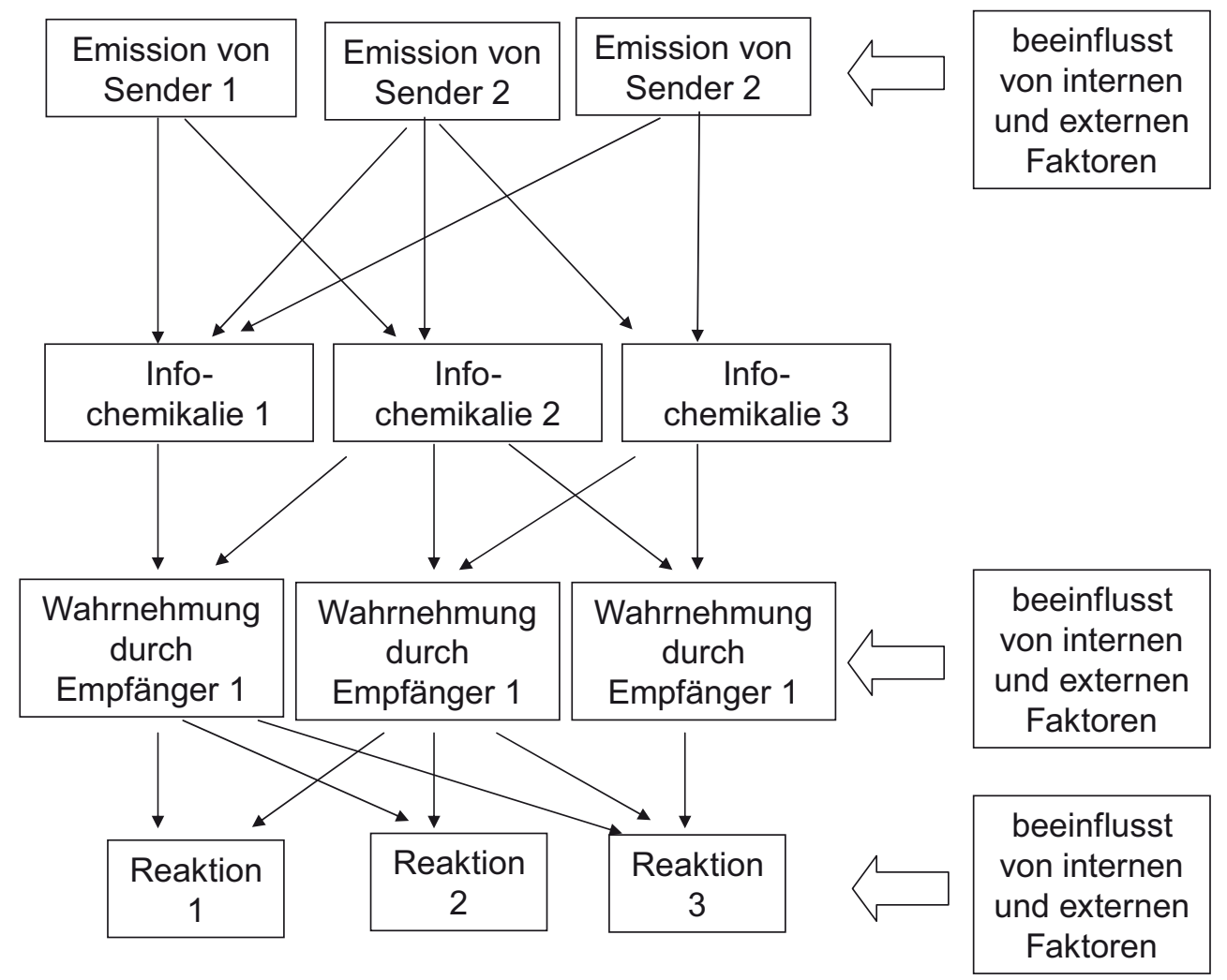

N-Verbindungen identifiziert (Klaschka 2008a,b). Die Anzahl der Infochemikalien, die in der Natur verwendet werden, scheint sehr groß zu sein, aber nicht unbegrenzt. So verwenden z.B. 4500 Schmetterlingsarten in Mitteleuropa nur ungefähr 150 verschiedene Stoffe als Sexualpheromone (Johnston 2000). Die Informationen sind noch zu heterogen, um Aussagen über die chemischen Gemeinsamkeiten von Infochemikalien bestimmter Gattungen oder Arten zu machen. Hier seien ein paar Beispiele für natürliche Infochemikalien aquatischer Organismen genannt. In Fischen wurden Aminosäuren, Aminosäurederivate und Neurotransmitter beschrieben (Hara 1992; Lipschitz und Michel 2002; Nikonov und Caprio 2004; Sato und Suzuki 2001; Speca et al. 1999), Polyamine (Rolen et al. 2003), Steroide wie z. B. Gallensäuren (Cao et al. 1998; Fine et al. 2004; Li und Sorensen 1997) oder Stickstoffoxide wie z. B. HypoxanthinN-oxid (Brown et al. 2003). Aminosäuren, verschiedene andere Stickstoffverbindungen und Gallensalze sind in unterschiedlichen Konzentrationen im Urin von Fischen enthalten (Sato und Suzuki 2001). Aliphatische Sulfate wurden in Kairomonen von Daphnia identifiziert (Yasumoto et al. 2006). Trimethylamin scheint ein weiterer Bestandteile des natürlichen Infochemikaliengemischs für Daphnia zu sein (Boriss et al. 1999). Wenn Proteine als Infochemikalien beschrieben wurden, wie bei vielen Insekten (Bradbury und Vehrencamp 1998; Pelosi et al. 2006), ist es nicht immer sicher, ob die Eiweiße auch die eigentlichen Infochemikali- en sind. Sie könnten auch als Träger der wirksamen Liganden fungieren, wie dies für Vertebraten beschrieben wurde (Johnston 2000). Infochemikalien können sich auf dem Weg von Sender zu Empfänger durch Abbau- oder Umbaureaktionen chemisch verändern. Daher ist es nicht immer einfach, herauszufinden, welche Substanz genau als Infochemikalie agiert (Bradbury und Vehrencamp 1998). Stereoisomere können sehr unterschiedlich wirken, wie z. B. auch bei der menschlichen Geruchswahrnehmung: R-(-)Carvon riecht wie Grüne Minze während S-(+)Carvon den Geruch von Kümmel hervorruft (Rossiter 1996). Interessanterweise können Chemikalien, die als Infochemikalien beschrieben wurden, gleichzeitig auch ganz andere Aufgaben erfüllen, z. B. die Haut schützen (Chivers et al. 2007). Duftstoffe und ätherische Öle können neben ihrer Funktion bei der chemischen Kommunikation auch Pflanzenfresser abwehren: Sie können Muskelkontraktionen hervorrufen oder spasmolytisch sein, das zentrale Nervensystem beeinflussen, die Ionenpermeabilität von Membranen oder den Blutdruck verändern, molluskizid sein oder als Antioxidans wirken (Lahlou 2004). Umgekehrt können Stoffe, die für die Ernährung oder Verteidigung bekannt sind, wie z. B. Aminosäuren oder spezifische Toxine, gleichzeitig als Infochemikalien agieren, wenn sie in der Umgebung eines Organismus freigesetzt werden. Eine Substanz kann eine Infochemikalie für eine Art sein, ein Nährstoff für eine andere und ein Toxin für eine dritte. In einigen Fällen ist es nicht klar, ob eine 
Substanz, die als Fraßschutz dient, ein intrazelluläres Toxin oder eine extrazelluläre Infochemikalie ist (Turner und Tester 1997). Es ist derzeit nicht möglich, und wahrscheinlich auch nicht notwendig und sinnvoll, zu entscheiden, welche der Funktionen vorrangig ist. Diese Ergebnisse zeigen, dass es nicht den natürlichen Verhältnissen entspricht, Infochemikalien, Toxine, Nährstoffe etc. in strikt getrennte Kategorien einzuteilen, sondern man muss sich darüber im Klaren sein, dass eine Verbindung in der Natur verschiedene Bedeutungen haben kann (Pohnert et al. 2007).

Es gibt mehrere Fälle, in denen man zuerst eine einzelne Substanz als verantwortlich für eine konkrete chemische Kommunikation identifizierte, und später Beweise dazu kamen, dass nicht nur eine, sondern mehrere Stoffe relevant waren (Johnston 2000). Offensichtlich erfolgt die Kommunikation über chemische Signale meist durch eine Infochemikalienmischung, die durchaus aus chemisch verwandten Stoffen zusammengesetzt sein kann. Der Empfänger reagiert z. B. nur dann spezifisch, wenn einige dieser Stoffe in einem bestimmten quantitativen Verhältnis vorliegen (z. B. Hilker et al. 2002). Ein Vergleich mit der menschlichen Geruchswahrnehmung hilft, besser zu verstehen, wie das funktionieren kann: Wir riechen keine Einzelverbindung im Duft von Lavendel, aber wir erkennen die lavendelspezifische Duftnote, wenn die entscheidenden Komponenten im richtigen Verhältnis vorliegen. Die Wahrnehmung von Duftgemischen entspricht zudem nicht einfach der Summe der Wahrnehmung der Einzelstoffe: Zou und Buck (2006) fanden heraus, dass Kombinationen von Duftstoffen andere Hirnareale aktivieren als die Einzelstoffe separat.

Die Vielfalt der chemischen Strukturen von Infochemikalien kann durch einige Überlegungen zu ihrer Herkunft verständlich gemacht werden (Klaschka 2008b). Die Substanzen können ursprünglich Nahrungsbestandteile oder Pflanzenmaterial gewesen sein (z. B. bei Insekten, Eltz et al. 2005). Die chemischen Signale von Räubern hängen von der zuvor gefressenen Beute ab (Ferrari et al. 2007). Infochemikalien können Gewebsbestandteile sein, die nach einer Verletzung freigesetzt werden. Schreckstoffe werden für Einzeller, Plattwürmer, Anneliden, Arthropoden, Mollusken, Fische und Amphibien beschrieben (Chivers et al. 1996). In mehreren Fällen stellte sich heraus, dass die chemischen Signale, die ursprünglich dem eukaryotischen Sender zugeschrieben worden waren, in Wirklichkeit Emissionen von Bakterien waren, die auf oder in dem betreffenden Organismus wuchsen. (Die Vielfalt der flüchtigen Stoffe, die Bakterien abgeben können, wurde von Schulz und Dickschat (2007) zusammengestellt.) Abbauprodukte, die von verletzten oder toten Organismen stammen, können als Nahrungslockstoffe dienen. Metaboliten und Abfallstoffe nach der Verdauung als Bestandteile in Kot und Urin sind wichtige Infochemikalien, die die Rangstellung männlicher Fische und Krabben anzeigen (Breithaupt und Eger 2002). Eine induzierte Synthese ist für einige spezifische Verbindungen wie Sexualpheromone anzunehmen. Reaktionen im extrazellulären Raum können bei allen genannten Quellen dazukommen. Die Stoffe werden durch Exkretion, Exozytose oder einfach durch Lecks im verletzten Gewebe oder durch Diffusion freigesetzt.

Je mehr über Infochemikalien bekannt wird, desto mehr wird deutlich, wie viele Organismen extrem empfindlich auf subtile chemische Signale in der Umwelt reagieren (Burks und Lodge 2002; Brönmark und Hansson 2000; Dodson et al. 1994; Wolfe 2000). Die hohe Sensitivität wurde z.B. für die Gallensäuren Allocholsäure und Petromyzonolsulfat gezeigt: Auf Konzentrationen von $10^{-9} \mathrm{Mol} / 1$ reagierte das Meeresneunauge noch spezifisch (Li und Sorensen 1997). Konzentrationen, die das Verhalten steuern, können 0,1$5,0 \%$ der LC50, die in ökotoxikologischen Standardtests gemessen werden (z. B. Letalität von Regenbogenforelle), betragen (Little et al. 1993). Neueste Erkenntnisse zeigen, wie schnell und präzise spezifische Duftkomponenten vor einem vielfältig zusammengesetzten Hintergrundgeruch in der Umwelt wahrgenommen werden können (Krofczik et al. 2009). Eine Substanz kann bei unterschiedlichen Konzentrationen qualitativ unterschiedliche Botschaften vermitteln. Jeder weiß, dass die Geruchswahrnehmung bei verschiedenen Konzentrationen qualitativ ganz anders sein kann: z. B. stinken hohe Konzentrationen von Methylsulfid wie faule Eier, in großer Verdünnung duftet es nach Spargel. Einige Infochemikalien sind identisch mit Substanzen, die in höheren Konzentrationen im Gewebe vorkommen. Sie können in einem Konzentrationsfenster zwischen den niedrigen Hintergrundwerten und den hohen Gewebskonzentrationen spezifisch als Infochemikalien wirken, und in diesem Bereich sind auch Dosis-Effekt-Beziehungen zu finden (Carr 1988; Klaschka 2008a) (Abb. 2). Leider wurden bisher nur für wenige natürliche Infochemikalien Dosis-Effekt-Kurven erstellt, z. T. auch ohne die Stoffe chemisch zu charakterisieren (Casotti et al. 2005; Ferrari und Chivers 2006a,b; Ferrari et al. 2008; Kusch et al. 2004; Li und Sorensen 1997; Matsumara et al. 2004; Rolen et al. 2003; Sengupta et al. 1996; Speca et al. 1999; Yamamoto et al. 2000).

\subsection{Bedeutung von Infochemikalien für die Empfänger}

Infochemikalien können Sexuallockstoffe, Schreckstoffe, Bestäuberlockstoffe oder Stoffe sein, die andere Botschaften vermitteln. Ein Stoff kann mehr als eine Nachricht übermitteln, daher ist der allgemeine Begriff Infochemikalien für die Vielfalt an chemischen Signalen vorzuziehen.

Dass Empfänger auf Infochemikalien reagieren, lässt sich an Veränderungen ihrer Physiologie, Morphologie oder ihrem Verhalten erkennen (Abb. 3). Eine angemessene Reaktion kann aus einer Kombination verschiedener Reaktionen bestehen, z.B. nutzt Daphnia eine umfassende Verteidigungsstrategie gegen Fraßfeinde, die aus verti- 


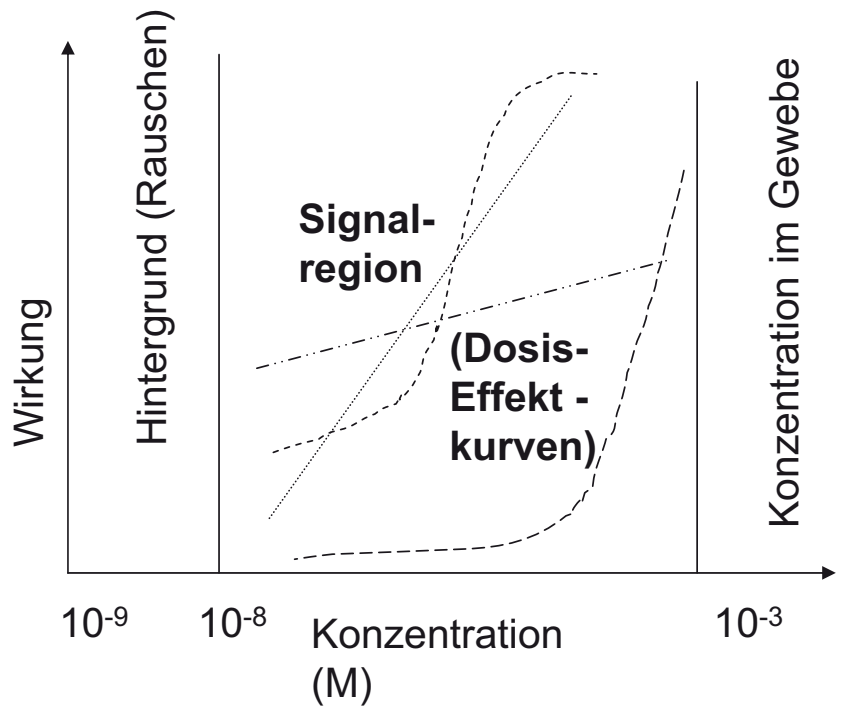

Abb. 2 Infochemikalien müssen nicht immer spezielle Verbindungen sein. Auch weitverbreitete Stoffe, die z. B. im Gewebe vorkommen, können in einem Konzentrationsfenster zwischen der Hintergrundkonzentration und der Konzentration im Gewebe als Infochemikalien fungieren. In diesem Bereich können Dosis-Wirkungs-Kurven beschrieben werden, was z. B. für Nukleotide oder Aminosäuren gezeigt wurde (Klaschka 2008a; Carr 1988)

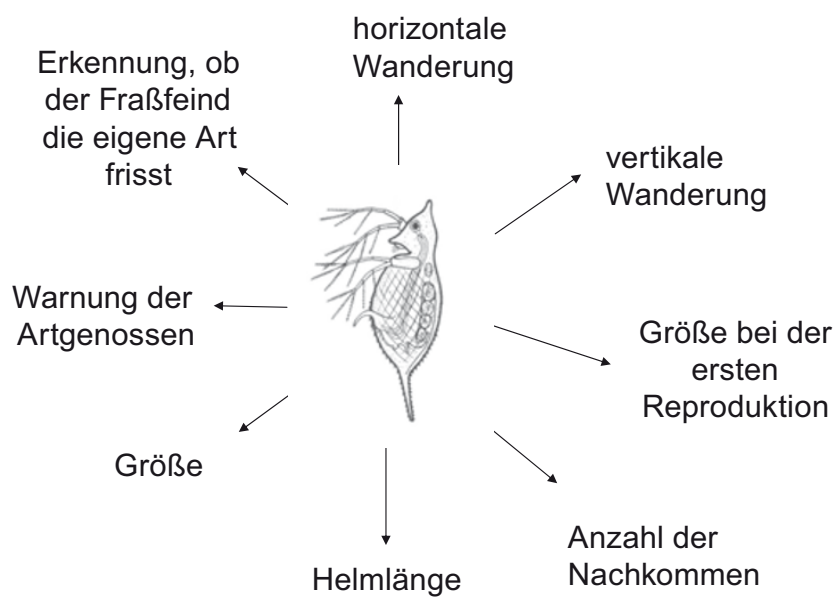

Abb. 3 Daphnia kann auf Infochemikalien durch morphologische, physiologische oder Verhaltenänderungen reagieren. Hier sind einige Beispiele dargestellt (Quellen s. Text)

kalen Wanderungen, reduziertem Wachstum, verzögertem Schlupf und der Ausbildung von Helmen bestehen (Boeing et al. 2006; Boersma et al. 1998; Burks et al. 2000; Mikulski 2001; Roozen und Lürling 2001; Stibor und Lampert 2000; Von Elert und Pohnert 2000; Weber 2001, 2003; Weber und van Noordwijk 2002; Yang et al. 2007). Intraspezifische Reaktionen auf Infochemikalien betreffen Artgenossen, z. B. wenn ein Sexualpartner angelockt wird, die Nachkommen erkannt und gefüttert werden oder Informationen über Fut-

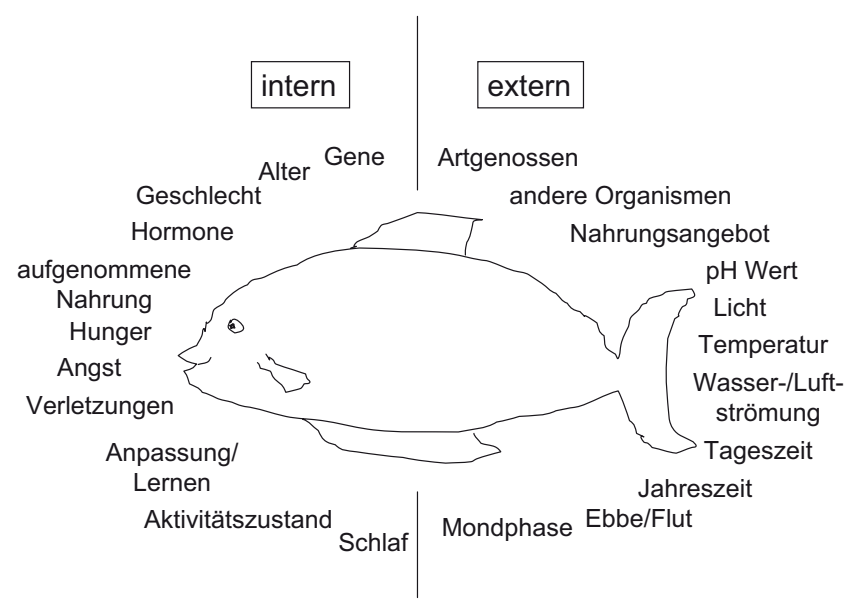

Abb. 4 Verschiedene Faktoren beeinflussen die Emissionen von Infochemikalien eines Senders und die Reaktionen eines Empfängers

ter oder Feinde ausgetauscht werden. Die Reaktionen können sich aber auch an andere Arten richten (Beute- oder Feinderkennung). Schreckstoffe können von Artgenossen, aber auch von Individuen anderer Arten, gedeutet werden, vor allem dann, wenn sie vom selben Feind gejagt werden.

Ein Organismus hat bei der Reaktion auf Umweltreize meist verschiedene Handlungsmöglichkeiten (z. B. Tomba et al. 2001; Shiojiri et al. 2006). Reaktionen eines Empfängers auf Infochemikalien sind nicht stereotyp, sondern hängen (genauso wie die Emission von Infochemikalien eines Senders) von inneren Faktoren (wie Alter, Geschlecht und Aktivitätszustand) ab. Das ist nichts Ungewöhnliches: Wir reagieren nach einer Mahlzeit anders auf Essensgerüche als bei Hunger. Auch externe Faktoren, wie Tages-/Jahreszeit oder Temperatur, beeinflussen die Reaktionen. Weitere Beispiele für interne und externe Faktoren, die die Emission von Infochemikalien durch den Sender und die Reaktionen des Empfängers beeinflussen können, sind in Abb. 4 dargestellt (Klaschka 2008a; Pollock et al. 2006; Prince et al. 2006; Smith et al. 2008).

Sogar für Pflanzen spielt die chemische Kommunikation eine wichtige Rolle: Bestäuber werden durch Blütendüfte angelockt. Pflanzen, die von Raupen befallen sind, locken mit Duftstoffen genau die passende Schlupfwespenart an, die die jeweiligen Raupen parasitiert (tritrophische Interaktion). Es gibt sogar Raupen, die genau dann diese Pflanzen meiden, um der Parasitierung zu entgehen (Shiojiri et al. 2006). Allelopathie (Pflanzen emittieren Verbindungen, die das Wachstum anderer Pflanzenarten reduzieren oder inhibieren) oder Phytoalexine (Substanzen, die Pflanzen als Verteidigung gegen Angreifer produzieren) sind weitere Beispiele für die große Verbreitung von Infochemikalien im Pflanzenreich (Boller 1995; Larcher 1995; Pichersky 2004).

Übersichtliche Auflistungen von konkreten Sendern/ Empfängern und entsprechenden Infochemikalien finden 
Tabelle 1 Zusammenfassung der Befunde über Infochemikalien (nach Klaschka 2008b)

Sender/Quellen von Infochemikalien

Chemische Strukturen

Anzahl der Stoffe in einer Mischung von Infochemikalien

Wirksame Konzentrationen

Empfänger von Infochemikalien

Riechrezeptorgene

Mögliche Reaktionen der Empfänger

Bedeutung von Infochemikalien für das Überleben

Mögliche zusätzliche Rollen von Infochemikalien

Substanzen mit Infochemikalien-Effekt
Vertreter aller Taxa

Artgenossen (Sexualpartner, Konkurrenten Verwandte, Nachkommen), Futter/Beute, Individuen anderer Arten, Bakterien, verletzte oder tote Organismen, andere Quellen, z. B. anthropogene Infochemikalien wie Duftstoffe

Nur wenige Stoffe identifiziert: z. B. Proteine, Peptide, Aminosäuren, Kohlenhydrate, Kohlenwasserstoffe, Aldehyde, Karbonsäuren, Lipide, Lactone, Steroide, Phenole, Terpene, Phosphatidylcholine, Stickstoffverbindungen, Oligosaccharide, Glykopeptide

Meist unbekannt

in einem Beispiel bis zu 300 verschiedene Stoffe

Meist sehr gering, bis zu nanomolar

Vertreter aller Taxa, Artgenossen und Mitglieder anderer Arten

In Vertebraten bis 1000 Gene, in Fischen ca. 100

Veränderung der Fortpflanzung und Entwicklung, z. B. Zellteilung, Wachstum, Paarung/Konjugation, Wachstum der Ovarien, Eiablage, Einkapselung und Induktion der Ruhephase, Schlüpfen von Dauerstadien, Aggregation, Koloniebildung, Quorum sensing (bei Bakterien)

morphologische Veränderungen wie die Bildung von Stacheln, Helmen, Kielen, Verkleinerung/Vergrößerung, Veränderung der Körperproportionen

Verhaltensänderungen wie erhöhte oder verminderte Nahrungsaufnahme, erhöhte oder verminderte gerichtete oder ungerichtete Fortbewegung, tägliche vertikale Wanderung, Phototaxis, Betreuung des Nachwuchses

Produktion oder Freisetzung von Toxinen oder Infochemikalien

Sexuelle Anziehung, Kopulation, Erkennung der Nahrung, des Nachwuchses, Markieren von Territorien, Schreckstoffe und Erkennen des Fraßfeindes, Anlocken von Bestäubern, tritrophische Interaktion von Pflanzen gegen Pflanzenfresser, Konkurrenz (z. B. Allelopathie, Phytoalexine)

Schutz der Haut, Nährstoffe, Abfall, extrazelluläre Gifte, Verteidigung gegen Pflanzenfresser

Anthropogene Stoffe, die in die chemische Kommunikation eingreifen

einige Duftstoffe, Pflanzenschutzmittel, Schwermetalle

bei den meisten Stoffen noch nicht untersucht sich in Dodson et al. (1994), Klaschka (2008a), Klaschka und Kolossa-Gehring (2007), Larsson und Dodson (1993) oder Polya (2003).

Tabelle 1 gibt eine zusammenfassende Übersicht über die Erkenntnisse zu Infochemikalien bei Umweltorganismen.

\section{Reaktionskette der chemischen Kommunikation}

Die Funktionsweisen von Infochemikalien lassen sich am besten verstehen, wenn man sich den schrittweisen Ablauf der Reaktionskaskade der chemosensorischen Signaltransduktion deutlich macht (Abb. 5). Das Grundprinzip der Chemoperzeption ist in den meisten mehrzelligen tierischen Organismen ähnlich: Nachdem Infochemikalien von Sendern abgegeben werden, erreichen sie nach Diffusion das Riechepithel eines Empfängers. Dort lagern sie sich an spezifische Riechrezeptorproteine an, was zur Bildung eines elektrischen Signals führt, welches zum zentralen Nervensystem weitergeleitet wird und dort die Geruchswahrnehmung hervorruft. Nach der Wahrnehmung kann der Empfänger, wie in Abschn. 1.3 beschrieben, mit physiologischen, morphologischen oder Verhaltensänderungen reagieren.

Es gibt strukturelle Gemeinsamkeiten der Geruchswahrnehmung über zahlreiche Taxa hinweg: primäre bipolare
Sinnesnervenzellen, an deren einer Seite Zilien in einer Schleimschicht in Kontakt mit der Umwelt treten, übernehmen die Erkennung der Geruchsstoffe, während das Neuron an der anderen Seite das Signal zum zentralen Nervensystem weiterleitet (Ache 1994). Über diese Gemeinsamkeiten hinaus gibt es große Unterschiede zwischen der Morphologie und Physiologie der Geruchserkennung bei den verschiedenen Tiergruppen, und es gibt noch enormen Forschungsbedarf. Beschreibungen der einzelnen Schritte der Reaktionskaskade finden sich in Ache und Restrepo (2000), Buck und Axel (1991), Dionne und Dubin (1994), Dryer (2000), Finger et al. (2000), Freitag et al. (1998), Galizia und Szyszka (2008), Hummel et al. (2005), Krieger und Breer (1999), Schild und Restrepo (1998), Young und Trask (2002), Zarzo (2007) und Zhao und Firestein (1999).

\section{Der Infochemikalien-Effekt}

Es gibt deutliche Indizien dafür, dass anthropogene Stoffe in die sensible Wahrnehmung eines Organismus eingreifen. Diese Wirkung heißt Infochemikalien-Effekt (Klaschka 2008b). Anthropogene Stoffe, die für den InfochemikalienEffekt verantwortlich sind, können an jedem Schritt der 


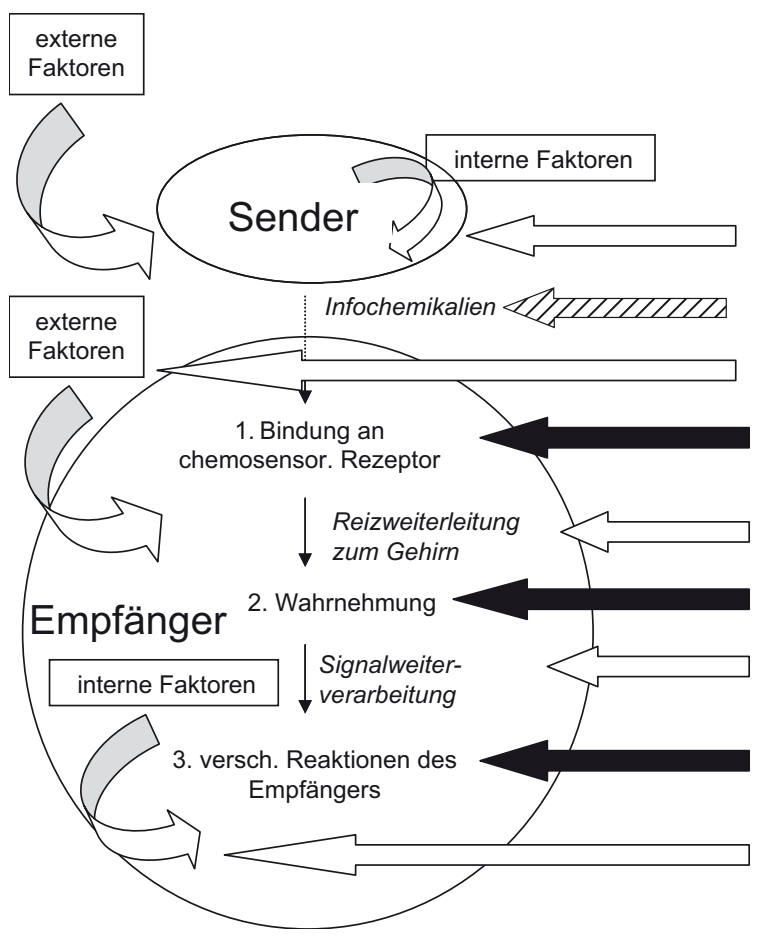

Abb. 5 Vereinfachtes Modell der Reaktionskette der chemischen Kommunikation durch Infochemikalien. Die möglichen Stellen, an denen anthropogene Infochemikalien eingreifen können, sind mit den waagrechten Pfeilen angedeutet. Der gestrichelte Pfeil ist ein Beispiel dafür, an welcher Stelle anthropogene Duftstoffe in die chemische Kommunikation eingreifen können. Die schwarzen Pfeile sind die drei Stufen, an denen sich experimentelle Prüfungen entwickeln lassen (Kap. 4)

chemosensorischen Signaltransduktion eingreifen, wie mit den waagrechten Pfeilen in Abb. 5 angedeutet ist.

Viele in Produkten eingesetzte Stoffe, die in die Umwelt eingetragen werden, sind chemisch identisch mit natürlichen Infochemikalien (gestrichelter Pfeil in Abb. 5). Das

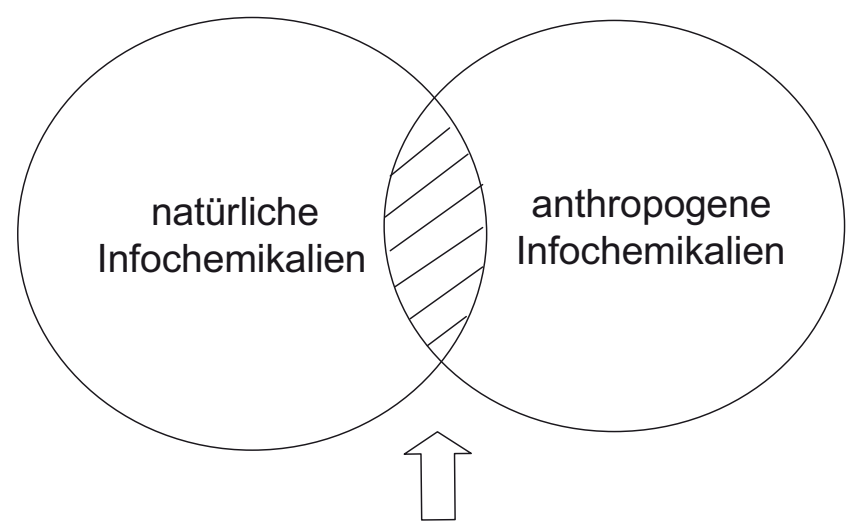

\section{z.B. einige Duftstoffe}

Abb. 6 Es gibt Beispiele von anthropogenen Infochemikalien, die chemisch gleich sind wie natürliche Infochemikalien, z. B. Duftstoffe, die in Kosmetika oder Wasch- und Reinigungsmitteln eingesetzt werden

gilt z.B. für viele Duftstoffe aus Kosmetika oder Waschund Reinigungsmitteln, die zu über $90 \%$ v. a. in das aquatische Kompartiment eingetragen werden und in der Natur als natürliche Infochemikalien identifiziert wurden (Abb. 6 und Tabelle 2, Klaschka und Kolossa-Gehring 2007). Empfänger können dann nicht zwischen natürlichen und anthropogenen Infochemikalien unterscheiden, da diese am selben Riechrezeptor binden. Nach Schätzungen liegen die eingetragenen Duftstoffmengen in Konzentrationsbereichen vor, die die Reaktionen auf Infochemikalien beeinflussen. Eine Erhöhung der Umweltkonzentration kann daher den entsprechenden Empfänger dieser Infochemikalie täuschen. Es gibt ganz konkrete Beispiele dafür: Japanische Forscher fanden heraus, dass Hornissen u. a. 2-Pentanol, einen Duftstoff aus Kosmetika, als Alarmpheromon erkennen und spe-
Tabelle 2 Auswahl einiger Stoffe, die in Parfümzubereitungen verwendet werden und ihre Rollen in der Natur (Klaschka und Kolossa-Gehring 2007)

\begin{tabular}{lll}
\hline Häufig eingesetzte Duftstoffe & C.A.S.-Nummer & Rolle als Infochemikalien in der Natur \\
\hline Benzaldehyd & $100-52-7$ & Sexualpheromon \\
Benzoesäure & $65-85-0$ & Phytoalexin \\
Kampfer & $76-22-2$ & Nahrungserkennung, Allelopathie, Reizung, \\
& $5392-40-5 ; 624-15-7$ & $\begin{array}{l}\text { Insektenabwehr } \\
\text { Ceimtötung, Nahrungserkennung, Signal für }\end{array}$ \\
Litral & $78-70-6$ & die Eiablage \\
Terpinylazetat & $80-26-2$ & \\
Citral & $5392-40-5 ; 624-15-7$ & Verteidigung, Keimtötung \\
Citronellal & $106-23-0$ & \\
Isopentenylazetat & $5205-07-2$ & Warnpheromone \\
alpha-, beta-Pinen & $7785-26-4,18172-67-3$ & Abwehr, Verteidigung, Allelopathie, Reizung \\
Salizylaldehyd & $90-02-8$ & Verteidigung, Hygiene \\
Terpinolen & $586-62-9$ & Nahrungserkennung, Warnpheromone \\
Tridecanon & $593-08-8$ & Abwehr \\
\hline
\end{tabular}




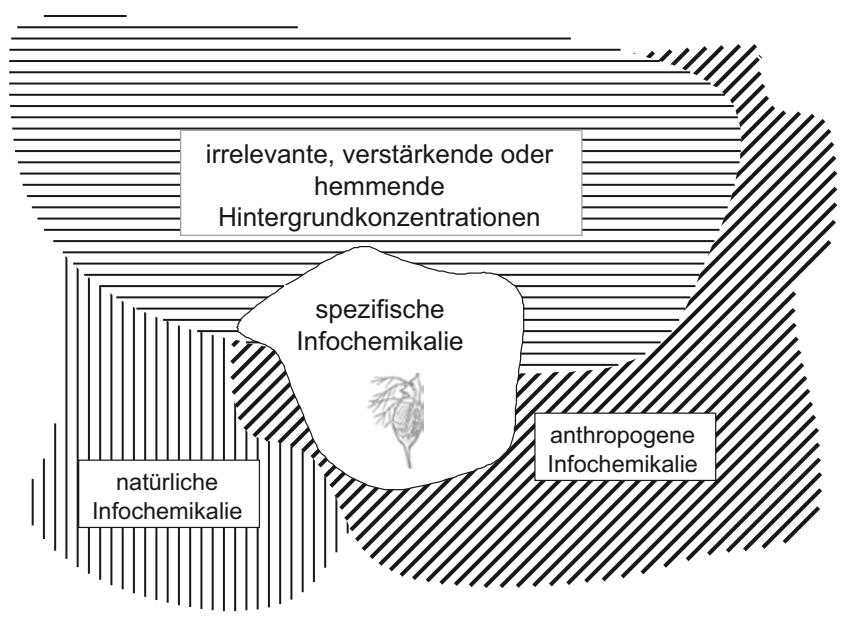

Abb. 7 Schematische Darstellung, wie Duftwolken sich überlagern können. Die natürlichen Infochemikalien, die z. B. von eine Daphnie emittiert werden, können durch Hintergrundwolken überlagert werden, die sowohl natürliche als auch anthropogene Infochemikalien sein können und die die Wirkung der Daphnien-spezifischen Infochemikalien hemmen, stärken oder nicht beeinflussen können

ziell Menschen angreifen, die Produkte mit diesem Stoff angewendet hatten (Ono et al. 2003).

Duftstoffe mit derselben chemischen Struktur wie natürliche Infochemikalien stellen die einfachste Möglichkeit dar, wie anthropogene Stoffe in der Reaktionskaskade eingreifen könnten. Es sind auch zahlreiche andere Mechanismen möglich: Anthropogene Infochemikalien können mit natürlichen Infochemikalien an den Riechrezeptorproteinen um die Bindungsstelle konkurrieren, sie können die Rezeptoren oder Neuronen vergiften, sie können mit den sekundären Botenstoffen interagieren oder sie können die Entwicklung eines funktionsfähigen chemosensorischen Gewebes stören. Anthropogene Infochemikalien können auch die Reaktionsmuster der Empfänger beeinflussen (Klaschka 2009). Sehr interessante Ergebnisse für Insekten zeigen, dass Hintergrunddüfte irrelevant für die Wahrnehmung einer Infochemikalie sein, diese maskieren oder verstärken können (Schröder und Hilker 2008). Alle drei Wirkungen sind auch für anthropogene Infochemikalien möglich, wie in Abb. 7 grafisch illustriert ist.

Nicht nur Duftstoffe, sondern auch Pestizide, Schwermetalle, Arzneimittelwirkstoffe, Neuromodulatoren oder andere Stoffe interferieren bei geringen subletalen Konzentrationen mit dem natürlichen chemischen Kommunikationssystem (Barry 2000; Czesnik et al. 2007; Hanazato 1999; Little et al. 1990; Lürling und Beekman 2002; Lürling et al. 2006; Lürling und Scheffer 2007; Michels et al. 2000; Moore und Lower 2001). Zum Beispiel haben die Pestizide Atrazin, Carbofuran, Diazinon und Simazin bei sehr geringen Konzentrationen negative Wirkungen auf die olfaktorische Erkennung des weiblichen Pheromons von Lachs (Moore und Lower 2001; Moore und Waring 1998;
Waring und Moore 1997). Unter bestimmten Bedingungen können Insektizide bei sehr geringen Konzentrationen einen ähnlichen Effekt auf die Morphologie und die Entwicklung von Daphnia haben wie natürliche Infochemikalien des Fraßfeindes (Barry 2000). Auch Stoffe, die das Riechepithel schädigen, beeinflussen die chemische Kommunikation und sind anthropogene Infochemikalien. Es ist schon lange bekannt, dass Metalle wie Cadmium (Michels et al. 2000), Zink, Kupfer, Quecksilber oder Silber das Riechepithel schädigen (Klaprat et al. 1992). Bei Cadmiumkonzentrationen, wie sie in der Umwelt vorkommen, können manche Fischarten keine Schreckstoffe mehr produzieren, um ihre Artgenossen zu warnen (Blechinger et al. 2007). Anthropogene Stoffe, die den $\mathrm{pH}-$ Wert des Wassers geringfügig verändern, können die chemische Kommunikation beeinflussen: Regenbogenforellen haben dann z. B. Probleme, die Infochemikalien ihrer Fraßfeinde zu lernen und sich diese zu merken (Smith et al. 2008). Weitere Beispiele sind in Klaschka (2008b) zusammengestellt.

Die Störung der chemischen Kommunikation kann gröBere negative Folgen für das Überleben einer Population haben als direkte toxische Effekte. Denn reduzierte Nahrungsaufnahme, das Nichterkennen eines Feindes, gestörtes Sexualverhalten oder anderes unpassendes Verhalten kann zu einem dramatischen Rückgang einer Population führen, auch wenn die Individuen völlig gesund sind. Das Ergebnis einer gestörten Kommunikation muss nicht immer an direkten Wirkungen am Individuum zu erkennen sein, sondern kann sich auch indirekt äußern, z. B. durch inter- oder intraspezifische Interaktionen, auf der Ebene der Population oder erst nach mehreren Generationen sichtbar werden (z. B. Agrawal et al. 1999; Fleeger et al. 2003; Verschoor et al. 2007). Organismen, die besonders stark auf die chemische Kommunikation angewiesen sind, sind einem besonderen Risiko ausgesetzt. Brown und Smith (1998) beschreiben einen Extremfall, wo Infochemikalien die zentrale Rolle bei einem starken Populationsrückgang spielen: Wenn Jungfische aus Fischzuchten freigesetzt werden, hatten sie keine Gelegenheit, Schreckstoffe von Feinden kennenzulernen. Sie fliehen nicht und werden leichte Beute, sodass nur wenige Tiere überleben.

In welchem Ausmaß anthropogene Infochemikalien Populationen in der Natur schwächen, ist derzeit schwer zu sagen. Es ist durchaus möglich, dass Organismen mit manchen anthropogenen Veränderungen gut zurechtkommen: Sie sind flexibel und verfügen über Strategien, um mit Störungen fertig zu werden: Zum Beispiel könnte die Mischung der natürlichen Infochemikalien so spezifisch sein, dass sich ein Organismus durch kleine Änderungen in den Hintergrundduftwolken nicht aus dem Konzept bringen lässt. Oder Populationen könnten aus genügend Individuen bestehen, sodass der Verlust durch Verständigungsprobleme nicht ins Gewicht fällt. Oder die Organismen könnten in der 
Lage sein, zu lernen (z.B. Brown und Chivers 2006), und die veränderte Zusammensetzung der chemischen Umgebung korrekt interpretieren. Welche Rolle solche Strategien als Schutz gegen den Infochemikalien-Effekt in der Natur spielen, muss erst noch untersucht werden.

\section{Testsysteme für den Infochemikalien-Effekt}

Es ist zu erwarten, dass anthropogene Infochemikalien zu schädigenden Wirkungen bei Organismen und Ökosystemen führen. Diese Hypothese verlangt nach experimenteller Überprüfung. Die derzeitigen ökotoxikologischen Standardtests decken den Infochemikalien-Effekt kaum ab, da häufig die Testdauern zu kurz, die gewählten Expositionskonzentrationen und die zu messenden Endpunkte nicht geeignet sind (Letalität/Immobilität versus morphologische oder Verhaltensänderungen), zudem kann man in Einzelspeziesansätzen keine interspezifische Kommunikation analysieren. Deshalb sollte man sich andere Testansätze überlegen.

Die Entwicklung geeigneter Testsysteme zur Quantifizierung des Infochemikalien-Effekts ist nicht banal, zumal man es mit einer Vielzahl relevanter Chemikalien, Rezeptoren und Reaktionen zu tun haben wird und die wirksamen Konzentrationen voraussichtlich sehr gering sind. Entsprechende Testansätze könnte man sich auf jeder der biologischen Komplexitätsniveaus vorstellen (Abb. 8). Das beste Vorgehen, um ein geeignetes Verfahren zu finden, ist eine systematische Prüfung entlang der Reaktionskaskade (Abb. 5). Dabei wurden entsprechend der schwarzen Pfeile in Abb. 5 folgende Möglichkeiten identifiziert: 1. Bindungsstudien an Riechrezeptoren zur Identifizierung von möglichen Riechstoffen durch In-situ-Hybridisierung oder immunohistochemische Tests, 2. Registrierung der Geruchswahrnehmung durch Messung elektrischer Signale von Riechsinneszellen im Gewebe (z. B. Elektroolfaktogramme, Elektroantennogramme), und 3. Reaktionen der Empfänger durch Nachweis der phänotypischen Veränderungen (z. B. mikroskopische Beobachtungen), Messung physiologischer Parameter, Verhaltenstests (z. B. In-situ-Onlinebiomonitoring, Verwendung von T-förmigen Olfaktometern, Untersuchung des Meideverhaltens), Messung von Populationsveränderungen (z.B. Bestimmung von Zelldichte oder Trübung) oder Mikro- und Mesokosmen, wobei die Struktur und die Funktion der Lebensgemeinschaft beobachtet werden kann.

Die vorgestellten Testsysteme in Tabelle 3 basieren auf Methoden der Grundlagenforschung der chemischen Ökologie und den Erkenntnissen über genetische Sequenzen für Riechrezeptoren, Bindungsstudien für Duftstoffe, Signalweiterleitung und Reaktionen der Empfänger auf der Ebene des Einzelorganismus oder der Population (Tabelle 4). Eine detailliertere Zusammenstellung der Möglichkeiten ist in Klaschka (2009) veröffentlicht.

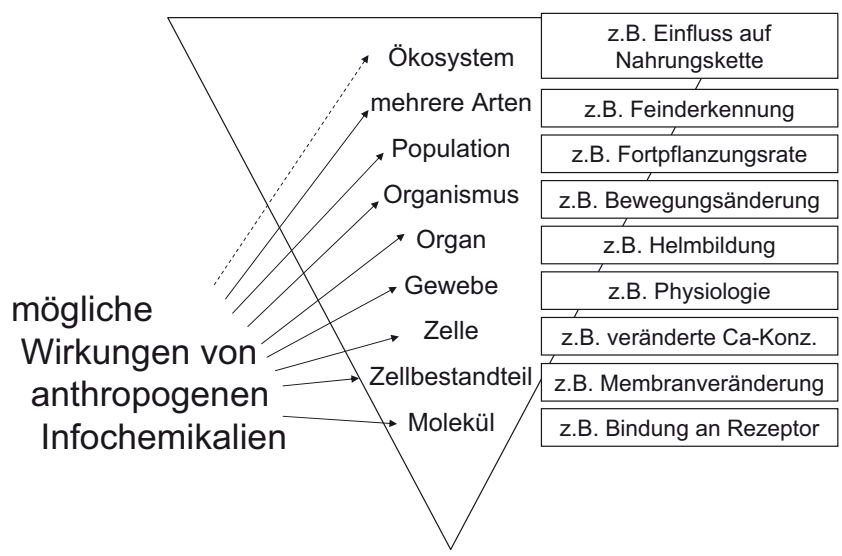

Abb. 8 Anthropogene Infochemikalien können auf verschiedenen biologischen Komplexitätsebenen wirken. Zur Verdeutlichung sind verschiedenen Möglichkeiten der Wirkungen von Infochemikalien auf Daphnia angegeben

Zur Abschätzung des Infochemikalien-Effekts auf die Umwelt sollten repräsentative Arten als Testorganismen eingesetzt werden. $\mathrm{Zu}$ vielen Tiergruppen wurden Untersuchungen zu verschiedenen Schritten in der Reaktionskette der chemischen Kommunikation durchgeführt (Tabelle 4). Dennoch ist aktuell die Datenlage noch zu dünn, um zu entscheiden, ob und wenn ja wie viele Kandidaten es gibt, die unter dem Aspekt Infochemikalien-Effekt als repräsentative Organismen angesehen werden könnten. Es spricht einiges dafür, mit den klassischen Standardorganismen der aquatischen Ökotoxikologie Daphnia und Fisch zu beginnen. Zum einen liegen vielfältige Informationen für sie zum Thema Infochemikalien vor und beide sind sowohl Sender als auch Empfänger von Infochemikalien. Sie sind gut geeignet für Verhaltenstests und Untersuchungen ihrer Morphologie und Physiologie. Außerdem lassen sich diese Ergebnisse leicht mit Ergebnissen kurzund längerfristiger Standardtests vergleichen.

Die systematische Zusammenstellung der möglichen Testsysteme führt zu dem Ergebnis, dass es in Anbetracht des großen Aufwands einiger Testansätze am besten wäre, ein schrittweises Vorgehen anzuvisieren. Dabei könnte der erste Schritt in einem relativ schnellen und günstigen Screeningtest bestehen, der mögliche anthropogene Infochemikalien auswählt. Geeignet sind dafür z.B. In-vitro-Bindungsstudien oder quantitative Strukturaktivitätsbeziehungen. Spezifischere Tests, wie z.B. Verhaltenstests, Beobachtungen der Populationsgröße oder Mikro- und Mesokosmen, wären dann in einem zweiten Schritt für den Nachweis notwendig, ob und wie ein Stoff tatsächlich als anthropogene Infochemikalie fungiert.

Die experimentelle Überprüfung des InfochemikalienEffekts führt zu dem Dilemma zwischen der offensichtlich extremen Komplexität der chemischen Kommunikation und der Notwendigkeit der Vereinfachung für durchführbare Labortests. Beim Infochemikalien-Effekt handelt es sich um 
Tabelle 3 Zusammenstellung der verschiedenen Anätze zur Messung des Infochemikalien-Effekt (Klaschka 2009)

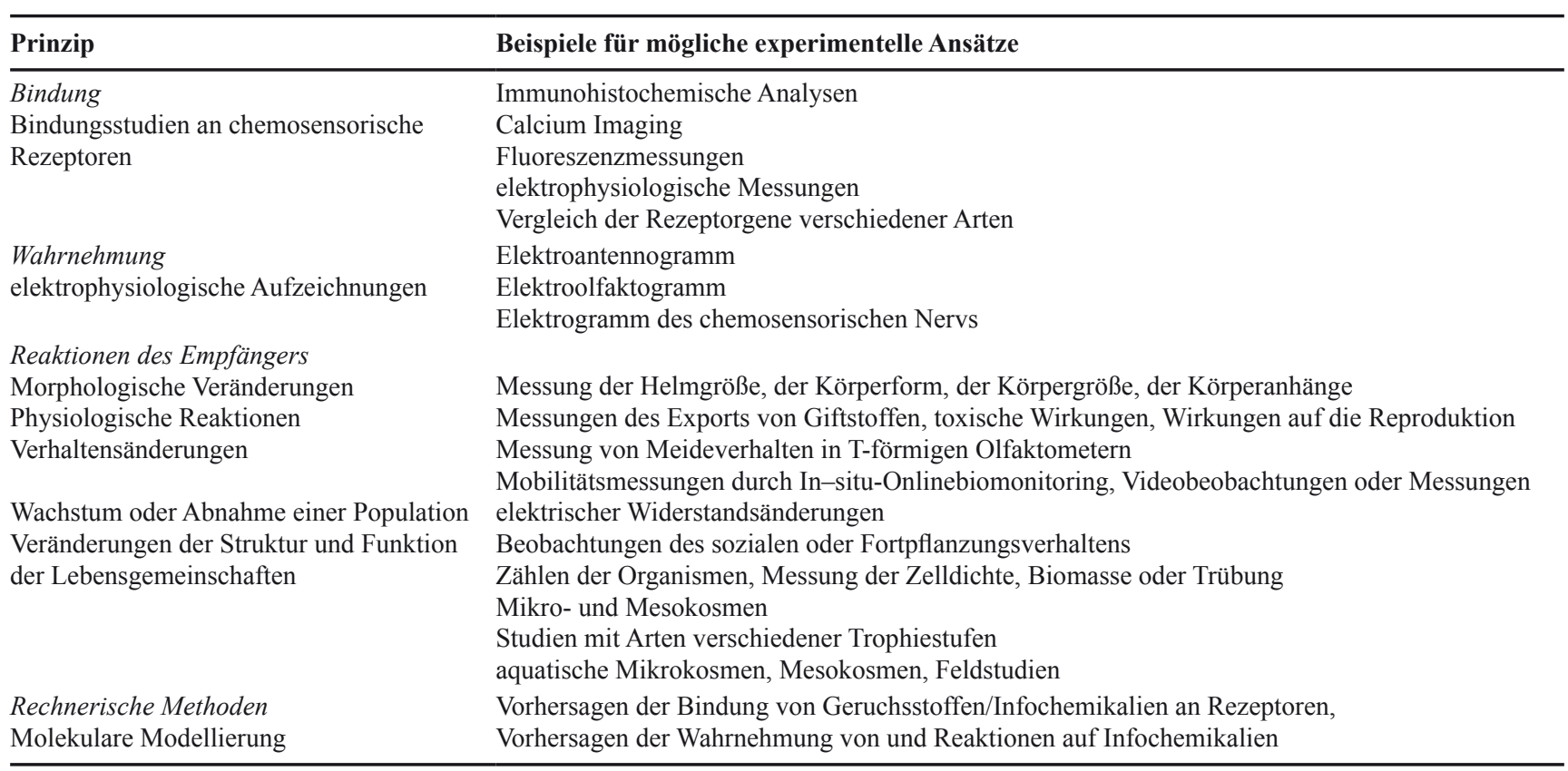

Tabelle 4 Mit vielen Tierarten wurden Untersuchungen zum Thema Geruchswahrnehmung und Infochemikalien durchgeführt. Ein Kreuz in einem Tabellenfeld bedeutet, dass zu einem bestimmten Themengebiet und einer Tiergruppe geeignete Methoden publiziert wurden. Diese Übersicht ist eine Zusammenfassung der ausführlichen Synopse in Klaschka (2009)

\begin{tabular}{lccccc}
\hline & $\begin{array}{c}\text { Rezeptoren (Gene } \\
\text { und Proteine) }\end{array}$ & $\begin{array}{c}\text { Bindungsstudien/ } \\
\text { elektrophysiologische } \\
\text { Messungen }\end{array}$ & $\begin{array}{c}\text { Bestimmung von } \\
\text { morphologischen } \\
\text { Veränderungen }\end{array}$ & $\begin{array}{c}\text { Verhaltenstests } \\
\text { Untersuchungen des } \\
\text { Lebenszyklus }\end{array}$ \\
\hline Bakterien & $\mathrm{X}$ & - & - & $\mathrm{X}$ & $\mathrm{X}$ \\
Protozoen & - & - & $\mathrm{X}$ & $\mathrm{X}$ & $\mathrm{X}$ \\
Rädertiere & - & - & - & $\mathrm{X}$ & - \\
Nematoden & $\mathrm{X}$ & $\mathrm{X}$ & $\mathrm{X}$ & $\mathrm{X}$ & $\mathrm{X}$ \\
Krebstiere & - & - & $\mathrm{X}$ & $\mathrm{X}$ & - \\
Insekten & $\mathrm{X}$ & $\mathrm{X}$ & $\mathrm{X}$ & $\mathrm{X}$ & $\mathrm{X}$ \\
Fische & $\mathrm{X}$ & $\mathrm{X}$ & $\mathrm{X}$ & - & - \\
Amphibien & $\mathrm{X}$ & - & - & - & \\
Säuger & $\mathrm{X}$ & $\mathrm{X}$ & & \\
\hline
\end{tabular}

eine Vielzahl verschiedener Dimensionen, die man prüfen könnte (Abb. 8). Eine vernünftige pragmatische Vereinfachung könnte z. B. dadurch gelingen, dass der komplexe Endpunkt Infochemikalien-Effekt in Unterpunkte geteilt wird und nur einer oder einige wenige Aspekte des Infochemikalien-Effekts gemessen werden.

\section{Schlussfolgerungen für Labor und Umweltschutz}

\subsection{Neue Erkenntnisse im Labor}

Die Bedeutung von anthropogenen Infochemikalien in der Umwelt und die Rolle von natürlichen Infochemikalien in
Labortests wurden bisher unterschätzt. Das Wissen um den Infochemikalien-Effekt wird dazu beitragen, einige bisher unverstandene Beobachtungen im Labor und in der Natur zu erklären. Effekte, die bisher als ,unspezifisch“ oder als „Artefakte“ beschrieben oder die sogenanntem „Stress“ zugeschrieben wurden, könnten auf die subtile Wirkung einer gestörten chemischen Kommunikation zurückzuführen sein. Zum Beispiel beeinflussten minimale Mengen von Substanzen, die aus Filtern gelöst wurden, den Testorganismus Scenedesmus (Lürling und Beekman 2002). Aufmerksame Experimentatoren, die sich des Infochemikalien-Effekts bewusst sind, werden voraussichtlich Erkenntnisse dazu sammeln können, ohne gezielt nach dem InfochemikalienEffekt gesucht zu haben. 
5.2 Berechnete Wirkwerte berücksichtigen

den Infochemikalien-Effekt nicht

Die computerbasierte Berechnung von ökotoxikologischen Ergebnissen ist im Vergleich zu Labortests finanziell attraktiv, spart Zeit und kommt dem Tierschutz entgegen. Ein Nachteil ist, dass die Resultate in erster Linie bei sogenannten „unspezifischen“ Wirkungen oder Wirkungen, deren Mechanismus man kennt, funktionieren. Der Infochemikalien-Effekt ist ein Beispiel für hochspezifische Wirkungen, deren Mechanismen man bisher nur ansatzweise kennt und damit ein Argument dafür, berechnete Wirkdaten sehr kritisch zu betrachten.

\subsection{Bedeutung von subletalen Wirkungen}

Der Infochemikalien-Effekt weist Parallelitäten mit den endokrinen Wirkungen von anthropogenen Stoffen, den Wirkungen von Arzneimittelwirkstoffen oder von Chemosensitizers (Stoffe, die die MXR-Transporter in der Zellmembran beeinträchtigen, Epel et al. 2008) auf, die in den vergangenen Jahren sehr viel Aufmerksamkeit auf sich gezogen haben. Infochemikalien wirken wie diese Stoffgruppen spezifisch, bei sehr niedrigen Konzentrationen, und es sieht so aus, als ob die Stoffvielfalt bei allen vier Gruppen groß ist. Subletale Wirkungen wie der Infochemikalien-Effekt können eine wichtige Rolle auf der Ebene der Populationen, der Lebensgemeinschaften oder der Ökosysteme spielen.

\subsection{Minimierungsgebot und Vorsorgeprinzip}

Dieser Übersichtsartikel zeigt, dass Stoffe Wirkungen auf die Umweltorganismen haben können, die bisher noch nicht beschrieben wurden. Daher sollte der Eintrag von Stoffen in die Umwelt grundsätzlich so gering wie möglich sein. Die Diskussion des Infochemikalien-Effekts bestätigt die Notwendigkeit des Minimierungsgebots und des Vorsorgeprinzips. Wenn genügend Kenntnisse vorliegen, sollte geprüft werden, ob der Infochemikalien-Effekt in der Risikobewertung von Chemikalien im Rahmen von REACh berücksichtigt werden muss.

\section{Was kann die Ökotoxikologie von der chemischen Ökologie lernen?}

Umweltorganismen sind einer Mischung aus natürlichen Infochemikalien ausgesetzt, bei der geringste Änderungen zu weitreichenden Folgen für ein Individuum oder eine Population führen können. In den vergangenen Jahren wurden verblüffende Details über natürliche Infochemikalien zu Tage gefördert. Diese Kenntnisse sind ausreichend, um daraus auf den Infochemikalien-Effekt zu schließen. Sie reichen jedoch nicht aus, die Ergebnisse direkt in die Ökotoxikologie zu transferieren, da noch unklar ist, wie sich der Infochemikalien-Effekt in der Umwelt konkret äußert. Solch ein Transfer ist jedoch nötig, um die anthropogene Belastung für die Umwelt zu verstehen und hoffentlich den Schutz der Umweltorganismen zu verbessern. Hier werden ähnliche Schwierigkeiten zu meistern sein, wie von Filser et al. (2008) für die Bodenökotoxikologie beschrieben wurde. Die Perspektive ist klar: Die besondere Bedeutung der chemischen Kommunikation rechtfertigt große Anstrengungen, um die ökologische Relevanz von anthropogenen Infochemikalien für das Ökosystem und für die Biodiversität besser einschätzen zu können.

Die Beschäftigung mit Infochemikalien öffnet die Augen für einen neuen Wirkmechanismus in der Ökotoxikologie. Sie führt zu einem neuen Verständnis der Interaktionen zwischen Organismen und ihrer Verletzlichkeit durch anthropogene Einträge. Einige Autoren verstehen die Brisanz des Infochemikalien-Effekts, indem sie schreiben: Da „... solche Chemikalien bei subletalen Konzentrationen (...) in die chemische Kommunikation eingreifen, wird es eine große Gruppe von bisher unbekannten Stoffen geben, die die Struktur der aquatischen Lebensgemeinschaften und Nahrungsnetzen in Seen und Meeren zerstören." (Pohnert et al. 2007, Zitat übersetzt von U.K.).

Es wird sicher noch Jahre dauern, bis geklärt ist, welche anthropogene Einträge zu Verständigungsproblemen bei Umweltorganismen führen können. Aber mit den heutigen Befunden ist jetzt deutlich geworden, wie großartig die Leistungen der Umweltorganismen sind und wie wichtig es ist, sie vor negativen Einflüssen zu schützen.

\section{Literatur}

Ache BW (1994) Towards a common strategy for transducing olfactory information. Semin Cell Biol 5:55-63

Ache BW, Restrepo D (2000) Olfactory Transduction. In: Finger TE, Silver WL, Restrepo D (eds) The neurobiology of taste and smell, 2nd edn. Wiley, New York, pp 167-177

Agrawal AA, Laforsch C, Tollrian R (1999) Transgenerational induction of defences in animals and plants. Nature 401:60-63

Atzmüller M, Grammer K (2000) Biologie des Geruchs: Die Bedeutung von Pheromonen für Verhalten und Reproduktion. Speculum 18(1):12-18

Barry MJ (2000) Effects of endosulfan on Chaoborus-induced lifehistory shifts and morphological defenses in Daphnia pulex. J Plankton Res 22:1705-1718

Blechinger SR, Matz C, Kusch RC, Chivers DP, Krone PH (2007) Brief embryonic cadmium exposure induces a stress response and cell death in the developing olfactory system followed by long-term olfactory deficits in juvenile zebrafish. Toxicol Appl Pharmacol 224:72-80

Boeing WJ, Ramcharan CW, Riessen HP (2006) Multiple predator defence strategies in Daphnia pulex and their relation to native habitat. J Plankton Res 28(6):571-584

Boersma M, Spaak P, de Meester L (1998) Predator-mediated plasticity in morphology, life history and behavior in Daphnia: the uncoupling of responses. Am Nat 152:237-248 
Boriss H, Boersma M, Witshire KH (1999) Trimethylamine induces migration of waterfleas. Nature 398:382-383

Boller T (1995) Chemoperception of microbial signals in plant cells. Annu Rev Plant Physiol Plant Mol Biol 46:189-214

Bradbury JW, Vehrencamp SL (1998) Principles of animal communication. Sinauer Associates, Sunderland USA

Breithaupt T, Eger P (2002) Urine makes the difference: chemical communication in fighting crayfish made visible. J Exp Biol 205:1221-1231

Brönmark C, Hansson LA (2000) Chemical communication in aquatic systems: an introduction. Oikos 88:103-109

Brown GE, Chivers DP (2006) Learning about danger: chemical alarm cues and predation risk assessment by fishes. In: Brown C, Laland K, Krause J (eds) Fish Cognition and Behaviour. Blackwell Sc Publ, Oxford, pp 49-69

Brown GE, Smith RJF (1998) Acquired predator recognition in juvenile rainbow trout (Oncorhynchus mykiss) conditioning hatcheryreared fish to recognize chemical cues of a predator. Can J Fisheries Aqua Sci 55:611-617

Brown GE, Adrian JC Jr, Naderi NT, Harvey MC, Kelly JM (2003) Nitrogen oxides elicit antipredator responses in juvenile channel catfish, but not in convict cichlids or rainbow trout: Conservation of the Ostariophysan alarm pheromone. J Chem Ecol 29:1781-1796

Buck L, Axel R (1991) A novel multigene family may encode odorant receptors: a molecular basis for odor recognition. Cell 65:175-187

Burks RL, Lodge DM (2002) Cued in: Advances and opportunities in freshwater chemical ecology. J Chem Ecol 28:1901-1917

Burks RL, Jeppesen E, Lodge DM (2000) Macrophyte and fish chemicals suppress Daphnia growth and alter life-history traits. OIKOS 88:139-147

Cao Y, Oh BC, Stryer L (1998) Cloning and localization of two multigene receptor families in goldfish olfactory epithelium. Proc Natl Acad Sci USA 95:11987-11992

Carr WE (1988) The molecular nature of chemical stimuli in the aquatic environment. In: Atema J, Fay RR, Popper AN, Tavolga WN (eds) Sensory biology of aquatic animals. Springer, Berlin, pp $3-27$

Casotti R, Mazza S, Brunet C, Vantrepotte V, Ianora A, Miralto A (2005) Growth inhibition and toxicity of the diatom aldehyde 2-trans, 4-trans-decadienal on Thalassiosira weissflogii (Bacillariophyceae) J Phycol 41 (1):7-20

Chivers DP, Mirza RS (2001) Predator diet cues and the assessment of predation risk by aquatic vertebrates: a review and prospectus. In: Marchlewska-Koj A, Lepri JJ, Müller-Schwarze D (eds) Chemical Signals in Vertebrates 9. Plenum Press, New York, pp 277-284

Chivers DP, Smith RJF (1998) Chemical alarm signalling in aquatic predator-prey systems: a review and prospectus. Écoscience $5: 338-352$

Chivers DP, Brown GE, Smith RJF (1996) Evolution of chemical alarm signals: attracting predators benefits alarm signal senders. American Naturalist 148:649-659

Chivers DP, Wisenden BD, Hindman CJ, Michalak TA, Kusch RC, Kaminskyj SGW, Jack KL, Ferrari MCO, Pollock RJ, Halbgewachs CF, Pollock MS, Alemadi S, James CT, Savaloja RK, Goater CP, Corwin A, Mirza RS, Kiesecker JM, Brown GE, Adrian JC Jr, Krone PH, Blaustein AR, Mathis A (2007) Epidermal „alarm substance" cells of fishes are maintained by non-alarm functions: possible defence against pathogens, parasites and UVB radiation. Proceedings of the Royal Society of London B 274:2611-2619

Czesnik D, Schild D, Kuduz J, Manzini I (2007) Cannabinoid action in the olfactory epithelium. PNAS 104(8):2967-2972

Dionne V E, Dubin AE (1994) Transduction diversity in olfaction. J Exp Biol 194:1-21
Dodson SI, Crowl TA, Peckarsky BL, Kats LB, Covich AP, Culp JM (1994) Non-visual communication in freshwater benthos: an overview. J N Am Benthol Soc 13:268-282

Dryer L (2000) Evolution of odorant receptors. Bio Essays 22:803810

von Elert E, Pohnert G (2000) Predator specifity of kairomones in diel vertical migration of Daphnia: a chemical approach. Oikos $88: 119-128$

Eltz T, Sager A, Lunau K (2005) Juggling with volatiles: Exposure of perfumes by displaying male orchid bees. J Comp Physiol 191:575-581

Epel D, Luckenbach T, Stevenson CN, Macmanus-Spencer LA, Hamdoun A, Smital T (2008) Efflux Transporters: Newly Appreciated Roles in Protection against Pollutants. Environ. Sci Technol 3914-3920

Ferrari MCO, Chivers DP (2006a) The role of latent inhibition in acquired predator recognition by fathead minnows. Can J Zool 84:505-509

Ferrari MCO, Chivers DP (2006b) Learning threat-sensitive predator avoidance: how do fathead minnows incorporate conflicting information? Animal Behav 71:19-26

Ferrari MCO, Messier F, Chivers DP (2006a) The nose knows: minnows determine predator proximity and density through detection of predator odours. Animal Behav 72:927-932

Ferrari MCO, Kapitania-Kwok T, Chivers DP (2006b) The role of learning in the development of threat-sensitive predator avoidance: the use of predator cue concentration by fathead minnows. Behav Ecol Sociobiol 60:522-527

Ferrari MCO, Brown MR, Pollock MS, Chivers DP (2007) The paradox of risk assessment: comparing responses of fathead minnows to capture-released and diet-released alarm cues from two different predators. Chemoecology 17:157-161

Ferrari MCO, Messier F, Chivers DP (2008) Threat-sensitive learning of predators by larval mosquitoes Culex restuans. Behav Ecol Sociobiol 62:1079-1083

Filser J, Koehler H. Ruf A, Römbke J, Prinzing A, Schaefer M (2008) Ecology meets soil ecotoxicology: Challenge and Chance. Basic Appl Ecol 9:346-355

Fine JM, Vrieze LA, Sorensen PW (2004) Evidence that petromyzontid lampreys employ a common migratory pheromone that is partially comprised of bile acids. J Chem Ecol 30(11):20912110

Finger TE, Silver WL, Restrepo D (eds) (2000) The neurobiology of taste and smell, 2nd edn. Wiley, New York

Fleeger JW, Carman KR, Nisbet RM (2003) Indirect effects of contaminants in aquatic ecosystems. Sci Total Environ 317:207-233

Freitag J, Ludwig G, Andreini P, Rössler P, Breer H (1998) Olfactory receptors in aquatic and terrestrial vertebrates. J Comp Physiol A 183:635-650

Galizia CG, Szyszka P (2008) Olfactory coding in the insect brain: molecular receptive ranges, spatial and temporal coding. Entomol Exp Appl 128:81-92

Hanazato T (1999) Anthropogenic chemicals (insecticides) disturb natural organic chemical communication in the plankton community. Environ Pollut 105:137-142

Hara TJ (1992) Mechanisms in olfaction. In: Hara TJ (ed) Fish chemoreception. Chapman and Hall, London, pp 150-170

Hilker M, McNeil J (2007) Chemical and behavioral ecology in insect parasitoids: How to behave optimally in a complex odorous environment? In: Wajnberg E, Bernstein C, van Alphen J (eds) Behavioral Ecology of Insect Parasitoids: From Theoretical Approaches to Field Applications. Blackwell, Oxford, pp 92-112

Hilker M, Kobs C, Varama M, Schrank K (2002) Insect egg deposition induces Pinus sylvestris to attract egg parasitoids. J Exp Biol 205:455-461 
Hummel P, Vaidehi N, Floriano WB, Hall SE, Goddard WA III (2005) Test of the binding treshold hypothesis for odorant receptors: Explanation of the differential binding of ketones to the mouse and human orthologs of olfactory receptor 912-93. Protein Sci 14:703-710

Johansson BG, Jones TM (2007) The role of chemical communication in mate choice. Biol Rev 82:265-289

Johnston RE (2000) Chemical communication and pheromones: The types of chemical signals and the role of the vomeronasal system. In: Finger TE, Silver WL, Restrepo D (eds) The neurobiology of taste and smell, 2nd edn. Wiley, New York, pp 101-127

Klaprat DA, Evans RE, Hara TJ (1992) Environmental contaminants and chemoreception in fishes. In: Hara TJ (ed) Fish chemoreception. Chapman and Hall, London, pp 321-341

Klaschka U (2008a) Odorants - Potent Substances at Minor Concentrations. The ecological role of infochemicals. In: Kümmerer K (ed) Pharmaceuticals in the environment. Sources, fate, effect and risks, 3rd edn. Springer, Berlin, pp 305-320

Klaschka U (2008b) The Infochemical Effect - a new chapter in ecotoxicology. Env Sci Pollut Res 15(6):448-458

Klaschka U (2009) A new Challenge: Development of Test Systems for the Infochemical Effect. Env Sci Pollut Res. DOI 10.1007/ s11356-008-0093-1

Klaschka U, Kolossa-Gehring M (2007) Fragrances in the environment: pleasant odours for nature? Environ Sci Pollut Res 14 (Special Issue) (1):44-52

Krieger J, Breer H (1999) Olfactory Reception in Invertebrates. Science 286:720-723

Krofcik S, Menzel R, Nawrot MP (2009) Rapid odor processing in the honeybee antennal lobe network. Front Comput Neurosci. Doi: 10.3389/neuro.10.009.2008

Kusch RC, Mirza RS, Chivers DP (2004) Making sense of predator scents: investigating the sophistication of predator assessment abilities of fathead minnows. Behav Ecol Sociobiol 55:551-555

Lahlou M (2004) Essential Oils and fragrance compounds: bioactivity and mechanisms of action. Flavour Fragr J 19:159-165

Larcher W (1995) Physiological plant ecology. Ecophysiology and stress physiology of functional groups. Springer, Berlin Heidelberg New York

Larsson P, Dodson S (1993) Invited Review: Chemical communication in planktonic animals. Arch Hydrobiol 129:129-155

Li W, Sorensen PW (1997) Highly independent olfactory receptor sites for naturally occurring bile acids in the sea lamprey, Petromyzon marinus. J Comp Physiol A 180:429-438

Lipschitz DL, Michel WC (2002) Amino Acid Odorants Stimulate Microvillar Sensory Neurons. Chem Senses 27:277-286

Little EE, Archeski RD, Flerov BA, Kozlovskaya VI (1990) Behavioral indicators of sublethal toxicity in rainbow trout. Arch Environ Contamin Toxicol 19:380-389

Little EE, Fairchild JF, DeLonay AJ (1993) Behavioral methods for assessing impacts of contaminats on early life stage fishes. Am Fish Soc Symposium 14:67-76

Lürling M, Beekman W (2002) Extractable substances (anionic surfactants) from membrane filters induce morphological changes in the green alga Scenedesmus obliquus (Chlorophyceae). Environ Toxicol Chem 21:1213-1218

Lürling M, Scheffer M (2007) Info-disruption: pollution and the transfer of chemical information between organisms. Trends Ecol Evol 22(7):374-379

Lürling M, Sargant E, Roessink I (2006) Life-history consequences for Daphnia pulex exposed to pharmaceutical carbamazepine. Env Toxicol 21:172-180

Matsumura K, Matsunaga S, Fusetani N (2004) Possible involvement of phosphatdylcholine in school recognition in the catfish, Plotosus lineatus. Zool Sci 21:257-264
Michels E, Semsari S, Bin C, de Meester L (2000) Effect of sublethal doses of cadmium on phototactic behaviour of Daphnia magna. Ecotox Env Saf 47:261-265

Mikulski A (2001) The presence of fish induces the quick release of offspring by Daphnia. Hydrobiologia 442:195-198

Moore A, Waring CP (1998) Mechanistic effects of a triazine pesticide on reproductive endocrine function in mature male Atlantic salmon (Salmo salar L.) parr. Pesticide Biochem Physiol 62:41-50

Moore A, Lower N (2001) The impact of two pesticides on olfactory-mediated endocrine function in mature male Atlantic salmon (Salmo salar L.) parr. Comparative Biochemistry and Physiology Part B: Biochem Molec Biol 129(2-3):269-276

Nikonov AA, Caprio J (2004) Odorant Specificity of Single Olfactory Bulb Neurons to Amino Acids in the Channel Catfish. J Neurophysiol 92:123-134

Ono M, Terabe H, Hori H, Sasaki M (2003) Components of giant hornet alarm pheromone. Nature 424:637-638

Pelosi P, Zhou JJ, Ban LP, Calvello M (2006) Review: Soluble proteins in insect chemical communication. Cell Mol Life Sci 63(13):1460-1466

Pichersky E (2004) Plant scents. What we perceive as a fragrant perfume is actually a sophisticated tool used to entice pollinators, discourage microbes and fend off predators. Am Sci 92:514-521

Pohnert G, Steinke M, Tollrian R (2007) Chemical cues, defence metabolites and the shaping of pelagic interspecific interactions. Trends in Ecol and Evol 22:198-204

Pollock MS, Pollock RJ, Chivers DP (2006) Effects of body size, body condition and breeding state on responses to alarm cues by fathead minnows. Can J Zool 84:1351-1357

Polya G (2003) Biochemical targets of plant bioactive compounds. A pharmacological reference guide to sites of action and biological effects. Taylor and Francis, London New York

Prince EK, Lettieri L, McCurdy KJ, Kubanek J (2006) Fitness consequences for copepods feeding on a red tide dinoflagellate: deciphering the effects of nutritional value, toxicity and feeding behaviour. Oecologia 147:479-488

Rolen SH, Sorensen PW, Mattson D, Caprio J (2003) Polyamines as olfactory stimuli in the goldfish Carassius auratus. J Exp Biol 206:1683-1696

Roozen F, Lürling M (2001) Behavioural response of Daphnia to olfactory cues from food, competitors and predators. J Plankton Res 23(8):797-808

Rossiter KJ (1996) Structure-Odor Relationships. Chem Rev 96:32013240

Sato K, Suzuki N (2001) Whole-cell response characteristics of ciliated and microvillous olfactory receptor neurons to amino acids. Pheromone candidates and urine in rainbow trout. Chem Senses 26:1145-1156

Schild D, Restrepo D (1998) Transduction mechanisms in vertebrate olfactory receptor cells. Physiol Rev 78:429-466

Schröder R, Hilker M (2008) The relevance of background odor in resource location by insects: A behavioral approach. Bio Sci 58:308-316

Schulz S, Dickschat JS (2007) Bacterial volatiles: the smell of small organisms. Nat Prod Rep 4:814-842

Sengupta I, Chou JH, Bargmann CI (1996) odr-10 encodes a seven transmembrane domain olfactory receptor required for responses to the odorant diacetyl. Cell 84:875-887

Shiojiri K, Ozawa R, Takabayashi J (2006) Plant Volatiles, Rather than Light, Determine the Nocturnal Behavior of a Caterpillar. PloS Biol. Doi:10.1371/journal.pbio.0040164

Smith JJ, Leduc AOHC, Brown GE (2008) Chemically mediated learning in juvenile rainbow trout. Does predator odour $\mathrm{pH}$ influence intensity and retention of acquired predator recognition? J Fish Biol 72:1750-1760 
Speca DJ, Lin DM, Sorensen PW, Isacoff EY, Ngai J, Dittman AH (1999) Functional identification of a goldfish odorant receptor. Neuron 23:487-498

Stacey N (2003) Hormones, pheromones and reproductive behavior. Fish Physiol Biochem 28:229-235

Stibor H, Lampert W (2000) Components of additive variance in lifehistory traits of Daphnia hyalina: seasonal differences in the response to predator signals. Oikos 88:129-138

Tomba AM, Keller TA, Moore PA (2001) Foraging in complex odor landscapes: chemical orientation strategies during stimulation by conflicting chemical cues. J N Am Benthol Soc 20:211-222

Turner JT, Tester PA (1997) Toxic marine phytoplankton, zooplankton grazers and pelagic food webs. Limnol Oceanogr 42(5):1203-1214

Verschoor AM, Zadereev YS, Mooij WM (2007) Infochemical-mediated trophic interactions between the rotifer Brachionus calyciflorus and its food algae. Limnol Oceanogr 52(5):2109-2119

Waring CP, Moore A (1997) Sublethal effects of a carbamate pesticide on pheromonal mediated endocrine function in mature Atlantic salmon (Salmo salar L.) parr. Fish Physiol Biochem 17:203-211

Weber A (2001) Interactions between predator kairomone and food level complicate the ecological interpretation of Daphnia laboratory results. J Plankton Res 23(1):41-46

Weber A (2003) More than one "fish kairomone"? Perch and stickleback kairomones affect Daphnia life history traits differently. Hydrobiologia 498:143-150

Weber A, van Noordwijk A (2002) Swimming behaviour of Daphnia clones: differentiation through predator infochemicals. J Plankton Res 24:1335-1348
Webster MM, Goldsmith J, Ward AJW, Hart PJB (2007) Habitat-specific chemical cues influence association preferences and shoal cohesion in fish. Behav Ecol Sociobiol 62:273-280

Wolfe GV (2000) The chemical defence ecology of marine unicellular plankton: Constraints, mechanisms and impacts. Biol Bull 198:225-244

Wyatt TD (2003) Pheromones and animal behaviour. University Press, Cambridge

Yamamoto K, Kawai Y, Hayashi T, Ohe Y, Hayashi H, Toyoda F, Kawahara G, Iwata T, Kikuyama S (2000) Silefrin, a sodefrin-like pheromone in the abdominal gland of the sword-tailed newt, $C y$ nops ensicauda. FEBS Lett 472:267-270

Yang Z, Kong F, Shi X, Xing P, Zhang Z (2007) Effects of DaphniaAssociated Infochemicals on the Morphology, Polysaccharides Content and PSII-Efficiency in Scenedesmus obliquus. Internat Rev Hydrobiol 92(6):618-625

Yasumoto K, Nishigami A, Kasai F, Kusumi T, Ooi T (2006) Isolation and absolute configuration determination of aliphatic sulfates as the Daphnia kairomones inducing morphological defense of a phytoplankton. Chem Pharmaceut Bull 54:271-274

Young JM, Trask BJ (2002) The sense of smell: genomics of vertebrate odorant receptors. Hum Mol Genet 11:1153-11607

Zarzo M (2007) The sense of smell: molecular basis of odorant recognition. Biol Rev 82(3):455-479

Zhao H, Firestein S (1999) Vertebrate odorant receptors. Cell Mol Life Sci 56:647-659

Zimmer RK, Butman CA (2000) Chemical signaling processes in the marine environment. Biol Bull 198:168-187

Zou Z, Buck L (2006) Combinatorial effects of odorant mixes in olfactory cortex. Science 311:1477-1481 